\title{
Effect of Surface Roughness on Jute Fiber Reinforced Polyester Composite using AWJM
}

\author{
Kalirasu S, Rajini N, Rajesh S, Naveen kumarK, Hariharasudhan J, Tirumangainarayanan N
}

\begin{abstract}
Roughness plays an important role in identifying how the real object interacts with the surrounding. The rough surface gets wear easily, so therefore the object manufacturing sector needs to get concentrate in it. Nowadays composite plays an important role as leading components with some good properties. So, the composite manufacturer needs to get more concentration on cutting technology. Other cutting technology, the tool wear is the most important drawbacks need to be considered. There is some non-traditional machining process in which the cutting tool is not used in it. In this work we use Abrasive water jet machine (AWJM) because it is one of the most used non-traditional machining process, which has no cutting tool and the mixture of abrasive particle of garnet 80 mesh and high-pressure water from the nozzle is used to cut the workpiece with some following parameters like stand-off distance $\left(S_{d}\right)$, feed rate $\left(V_{f}\right)$ and water pressure $(P)$. The jute fiber reinforced polyester composite (JF/UPR) fabricated by compression moulding which is used for measuring surface roughness $(R a)$ and also to find the minimum Ra.
\end{abstract}

Keyword: Composites, AWJM Cutting, and Surface Roughness.

\section{INTRODUCTION}

Composite materials are used increasingly in highperformance applications because of their superiorspecific strength and stiffness. However, the macroscopically distinct multi phases of the material structure make such materials difficult to machine with conventional tools. [1] In traditional way machining there are some notable demerits that affect the whole machining process, time, material and money. [2] The machining tolerance, Dimensional Accuracy, Surface finish are some of the important factors that affect the workpiece. [3] In order to have good accuracy and better machining process the use of Non-Conventional machining came to trend in the world of Mechanical Engineering. [4] AWJM stands for Abrasives Water Jet Machining. It is one of the NonConventional Machining in recent trends.

Revised Manuscript Received on November 15, 2019.

S.Kalirasu*, Associate Professor, Department of Mechanical Engineering, Kalasalingam Academy of Research and Education, Krishnankoil-626126, Tamilnadu, India. Email: kalirasu.s@gmail.com.

N. Rajini, Professor, Department of Mechanical Engineering, Kalasalingam Academy of Research and Education, Krishnankoil-626126, Tamilnadu, India. Email: rajiniklu@gmail.com

S. Rajesh, Associate Professor, Department of Mechanical Engineering, Kalasalingam Academy of Research and Education, Krishnankoil-626126, Tamilnadu, India. Email: s.rajesh@klu.ac.in

K.Naveen kumar, J.Hariharasudhan, N. Tirumangainarayanan, UG Students, Department of Mechanical Engineering, Kalasalingam Academy of Research and Education, Krishnankoil-626126, Tamilnadu, India.
[5] In AWJM the machining is done by using abrasives and water. [6] The size of abrasives and the pressure of water plays a vital role in this machining process. [7] The abrasive size are ranging from 90-120 values. The pressure ranges from 90-120 bar for cutting the workpiece. [8] Using AWJM needs a large workspace. AWJM also includes a water tank, R-O Treated plant, Water jet machining with jet and other accessories. [9] This advanced machining results in the accurate cutting of workpiece, good surface finish, etc..., [10] The cutting angle can also be changed by tilting or changing the angle of the jet to have a cross-cut machining process and other cutting processes. [11] The AWJM involves low capital cost and ease of operation. We can also drill the workpiece and provide a cavity on the surface of the workpiece. Brittle materials like Glass, Ceramics, and Glass can be machined. [12] Using AWJM do not cause any hardening of the workpiece. The surface finish may vary as per the size of abrasives.

\section{II.EXPERIMENTAL DETAILS}

\section{A. Materials used}

Jute fibers are used for the fabrication of the composite plate. To reinforce the fiber, polyester resin is applied. These were supplied by vasavibala resins (P) Ltd, Chennai.

\section{B. Preparation of composite}

The jute fiber (JF) is cut into the shape of the mould in size of $30 \times 13 \mathrm{~cm}$ and then polished wax is applied over the moulds to remove the plate after fabrication with ease and then the required amount of polyester resin is taken. The jute fiber of $250 \mathrm{~g}$ is placed in the mould cavity and the unsaturated polyester resin (UPR) is gradually spread over the JF and it is covered by upper mould. And it is subjected to compression moulding about to a pressure of $120 \mathrm{psi}$ and it takes around 4 hours for curing time. After curing of fiber it is been removed off from the compression moulding the excess resins and fibers are been trimmed off. And the plate that we required for the testing has been obtained at the weight of 450gand the percentage of JF is calculated by dividing the weight of fiber by composite weight we obtain $55 \%$. Now, this can be used for the next process. 


\section{Effect of Surface Roughness on Jute Fiber Reinforced Polyester Composite using AWJM}

\section{MACHINING AND MEASUREMENTS}

\section{A. Cutting of plate through AWJM}

Figure 1. Shows the AWJ machine nozzle setup. The fabricated JF/UPR composite is placed on the work table of AWJM machine with the availability of specified garnet 80 mesh abrasive particles with a mixture of water for cutting the plate as per given input of $\mathrm{V}_{\mathrm{f}}, \mathrm{P}, \mathrm{S}_{\mathrm{d}}$. The plate has been cut into 54 pieces of $2 \mathrm{~cm}$ to measure the $\mathrm{Ra}$ of the plate by varying the above parameters.

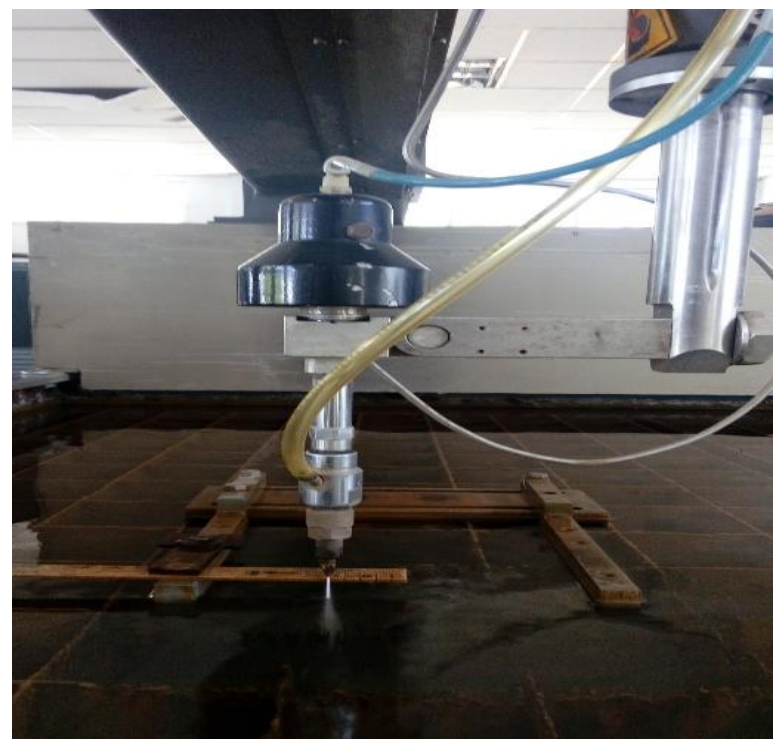

Fig. 1. Abrasive water jet machine nozzle setup

\section{B. Measurement of Ra}

The surface roughness of the fabricated JF/UPR composites is determined by Ra testing machine. Place the measuring probe properly and check it out without any error. Now place the workpiece on the table and now adjust the adjuster to touch tip of the fibre up to the indication of the green light and also give input of length of material for identification purpose for the machine is up to $20 \mathrm{~mm}$ and now start the machine and now the probe moves from the one end to other end and retains to the starting point. Now the readings are been displayed at the monitor as per this following the remaining readings are been noted and finally, the 54 different values are been formed as table format for easy identification of the measuring of minimum $\mathrm{Ra}$ of the specified abrasive particle on this composite material.

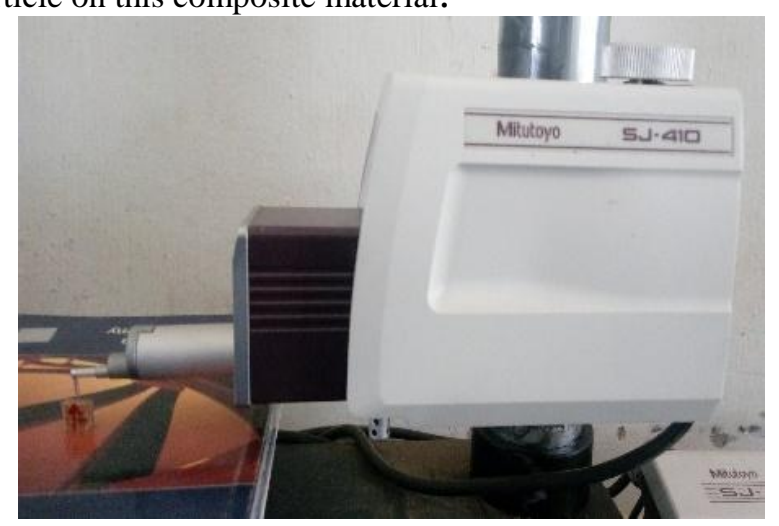

Fig. 2. Surface roughness testing machine
Table - I: Parameters and Levels

\begin{tabular}{|c|c|c|c|c|}
\hline \multirow{2}{*}{ S.No } & \multirow{2}{*}{ Parameters } & \multicolumn{3}{|c|}{ Levels } \\
\cline { 3 - 5 } & & $\boldsymbol{I}$ & $\mathbf{2}$ & $\mathbf{3}$ \\
\hline 1. & $\mathrm{P}$ & 150 & 200 & 250 \\
\hline 2. & $\mathrm{~S}_{\mathrm{d}}$ & 1 & 2 & 3 \\
\hline 3. & $\mathrm{~V}_{\mathrm{f}}$ & 20 & 30 & 40 \\
\hline
\end{tabular}

Table I.indicates the parameters and levels which are the different parameters with the different levels have been done on our research work. As a result of this experiment, we got three graphs which indicates the relationship between the Ra versus three different parameters.

\begin{tabular}{|c|c|c|c|c|}
\hline S.No & $\mathbf{P}(\mathbf{M p a})$ & $\mathbf{S}_{\mathbf{d}}(\mathbf{m m})$ & $\mathbf{V}_{\mathbf{f}}(\mathbf{m m} / \mathbf{s})$ & $\mathbf{R}_{\mathbf{a}}(\boldsymbol{\mu m})$ \\
\hline 1. & 250 & 1 & 20 & 0.07 \\
\hline 2. & 250 & 1 & 30 & 0.20 \\
\hline 3. & 250 & 1 & 40 & 0.57 \\
\hline 4. & 250 & 1 & 20 & 0.07 \\
\hline 5. & 250 & 2 & 20 & 0.27 \\
\hline 6. & 250 & 3 & 20 & 0.37 \\
\hline 7. & 150 & 1 & 20 & 0.33 \\
\hline 8. & 200 & 1 & 20 & 0.18 \\
\hline 9. & 250 & 1 & 20 & 0.07 \\
\hline
\end{tabular}

Table - II: RA Readings

Table II. Indicates the input given to the machine in order to find the Ra of JF/UPR composite, the main aim of this work is to identify the Ra with different input parameters with the help of AWJM. JF/UPR composites with the dimensions of $30 \mathrm{~cm} \times 13 \mathrm{~cm}$ which is placed in AWJM with some integrated joints. Therefore, the plate is fixed. And finally, the feed rate, pump pressure, and stand-off distance have been mentioned in the table as a result of the input parameter based on the value, the surface roughness is obtained. Each and every feed rate has different surface roughness, therefore when each input parameters change according to that surface roughness will get varied based on the input which was given.

\section{RESULTS AND DISCUSSIONS}

Fig 3(a) represents the relationship between the $\mathrm{Ra}$ versus $V_{f}$. This graph shows the three different feed rate with some specific parameters to know the surface roughness. This graph has clearly shown that if the feed rate increases the surface roughness will get increased when the input parameters with the pressure $250 \mathrm{MPa}$, stand-off distance $1 \mathrm{~mm}$, and the material are JF/UPR composites. 
To achieve the surface smoothness, the feed rate needs to be decreased. This means that the feed rate must be some specific but main drawback of this parameter, as feed rate decrease the cutting time will get decreased. It leads to slow down the manufacturing process. It means time consumption is high.

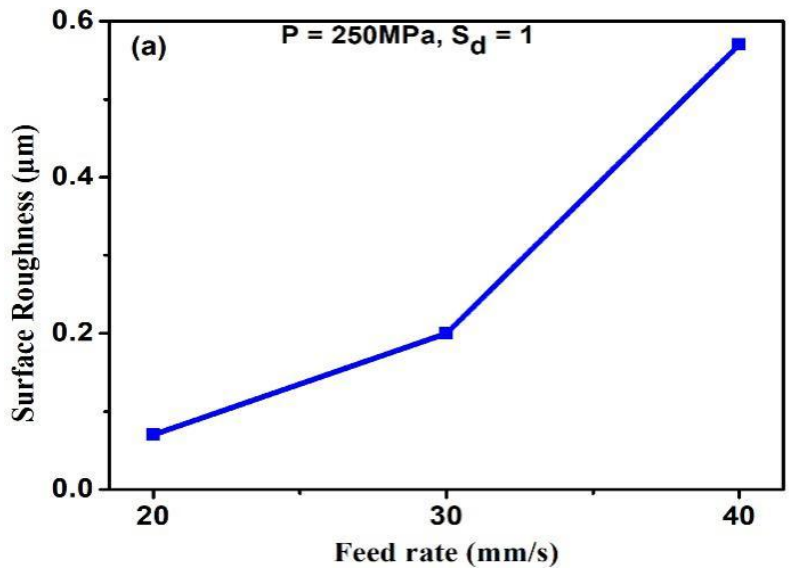

Fig. 3(a). Effect of $\mathrm{V}_{\mathrm{f}}$ at $\mathrm{P}=250 \mathrm{MPa}, \mathrm{S}_{\mathrm{d}}=1 \mathrm{~mm}$

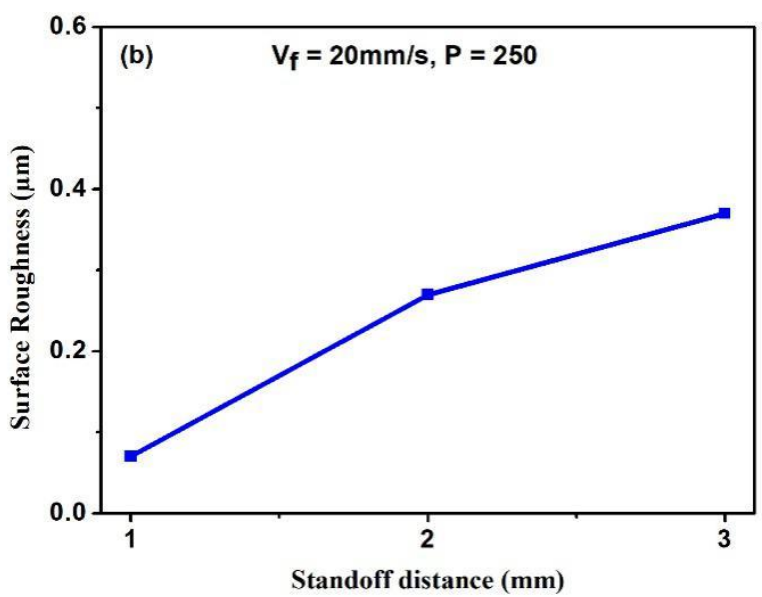

Fig. 3(b). Effect of $S_{d}$ at $P=250 M P a, V_{f=20} \mathrm{~mm} / \mathrm{s}$

Fig 3(b) represents the relationship between the $\mathrm{Ra}$ versus stand-off distance. This graph shows the comparative value with three different stand-off distance with some specific parameters. This graph has clearly shown that if the stand-off distance increases then the surface roughness will get increased, when the input parameters with the pressure $250 \mathrm{Mpa}$, feed rate $20 \mathrm{~mm} / \mathrm{s}$ and the material is JF/UPR composites. To achieve the surface smoothness, stand-off distance needs to be decreased. This means that the standoff distance must be some specific but main drawback of this parameter, as stand-off distance decrease the cutting time will get decreased as same as feed rate versus surface roughness. Once again time consumption is high with the stand-off distance parameter. This two-parameter results in time-consuming but the third parameter is different. The pressure is different from the other two parameters. With these two parameters, we can say that the AWJM is not suitable for composite materials.

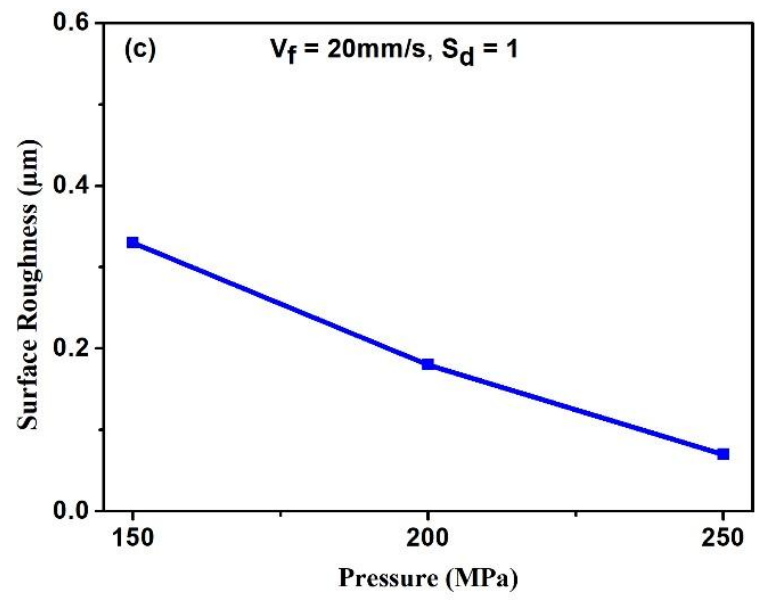

Fig. 3(c). Effect of Pressure at $S_{d}=1 \mathrm{~mm}, V_{f=20 m m} / \mathrm{s}$

Fig 3(c) represents the relationship between the surface roughness versus pressure. This graph shows the three different pressures with some specific parameters to know the surface roughness. This graph has clearly shown that if the pressure increases the surface roughness will get decreased when the input parameters with the feed rate $20 \mathrm{~mm} / \mathrm{s}$, stand-off distance $1 \mathrm{~mm}$, and the material are JF/UPR composites. Surface smoothness has been achieved. This shows that whatever the feed rate and standoff distance, the pressure needs to be more specific than others. The pressure is the outstanding parameter, with this we can say that the composite materials can be processed in AWJM.

\section{CONCLUSION}

From the testing of surface roughness of the JF/UPR composite material, we have found that by varying the feed rate and the other two parameters remaining constant. We noted an increase in feed rate also increases the $\mathrm{Ra}$ of the material. Then by varying the $S_{d}$ and other parameters remaining constant we noted an increase in $S_{d}$ also an increase in the surface roughness of the material. Then by varying the pressure and other parameters remains constant and there we found the increase in the pressure leads to decreases in the surface roughness. Then by determining all three parameters pressure $(250 \mathrm{MPa}), \mathrm{S}_{\mathrm{d}}(1 \mathrm{~mm})$ and $\mathrm{V}_{\mathrm{f}}(20 \mathrm{~mm} / \mathrm{s})$ we found the minimum surface roughness on this jute fiber reinforced polyester composite.

\section{REFERENCES}

1. S. Abrate, D. Walton, 'Machining of composite materials part-II: Nontraditional methods,; Compos. Manuf., vol. 3(2), 1992, pp. 85-94.

2. M. Ramulu, D. Arola, "Water jet and abrasive water jet cutting of unidirectional polyester composite," J. Compos., vol. 24(4), 1993, pp. 299-308.

3. J. Wang, W. C. K. Wong, "A study of abrasive water jet cutting of metallic coated sheet steels," Int. J. Mach. Tool. Manu,, vol. 39, 1999, pp. $855-870$.

4. J. Wang, D. K. Shanmugam, "Cutting meat with bone using an ultrahigh pressure abrasive water jet,” Meat Sci., vol. 81(4), 2009, pp. 671-677.

5. H. Ho-Cheng, "A failure analysis of water jet drilling in composite laminates,” Int. J. Mach. Tool. Manu.vol. 30(3), 1990, pp. 423-429. 
6. M. d. Nuruzzaman Khan, Juganta K. Roy, Nousin Akter, Haydar U. Zaman, Tuhidul Islam, and Ruhul A. Khan, "Production and Properties of Short Jute and Short E-Glass Fiber Reinforced Polypropylene-Based Composites," Open J. Compos. Mater, vol. 2, 2012, pp. $40-47$.

7. M. KanthaBabu, O. V. KrishnaiahChetty, "A study on recycling of abrasives in abrasive water jet machining," Wear, vol. 254(7-8), 2003, pp. 763-73.

8. Ibrahim Sen, Ayse Aral, Yoldas Seki, Mehmet Sarikanat, Kutlay Sever, "Variations of mechanical properties of jute/polyester composite aged in various media," J. Compos. Mater., vol. 46, 2012, pp. 2219-2225.

9. D. Ray, B. K. Sarkar, N. R. Bose, "Impact fatigue behaviour of vinylester rein matrix composites reinforced with alkali treated jute fibres," Compos. Part A., vol. 33, 2002, pp. 233-241.

10. S. Mishra, A. K. Mohanty, L. T. Drzal, M. Misra, S. Parija, S. K. Nayak, and S. S. Tripathy, "Studies on mechanical performance of jute/glass reinforced polyester hybrid composites," Compos. Sci. Technol., vol. 63, 2003, pp. 1377-1385.

11. R. Mohan, Kishore, M. K. Shridhar, R. M. V. G. K. Rao, "Compressive strength of jute-glass hybrid fibre composites," J. Mater. Sci. Lett., vol. 2, 1983, pp. 99-102.

12. A. N. Shah, S. C. Lakkad, "Mechanical properties of jute reinforced plastics,” Fiber Sci. Technol., vol.15, 1981, pp. 41-46.

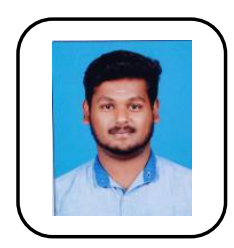

K. Naveen kumar, UG Student, Mechanical Engineering Department, Kalasalingam Academy of Research and Education, krishnankoil, Tamilnadu, India.

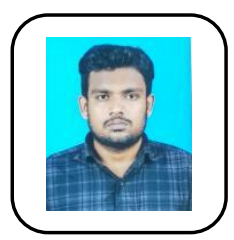

J. Hariharasudhan, UG Student, Mechanical Engineering Department, Kalasalingam Academy of Research and Education, krishnankoil, Tamilnadu, India.

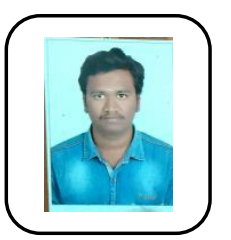

N. Tirumangainarayanan, UG Student, Mechanical Engineering Department, Kalasalingam Academy of Research and Education, krishnankoil, Tamilnadu, India.

\section{AUTHORS PROFILE}

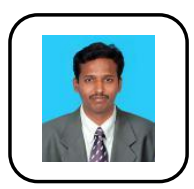

Dr. S. Kalirasu obtained his Bachelor's degree in Automobile engineering from K.L.N.College of Engineering; Madurai affiliated to Anna University, Chennai in 2009. He was awarded his Master's degree in CAD/CAM from Kalasalingam University, Krishnankoil in 2012. Then he was awarded his $\mathrm{PhD}$ in Mechanical Engineering from Kalasalingam Academy of Research and Education, Krishnankoil in 2018, He has published 10 international journals and also published more than 10 papers in International Conference proceedings. His research interest is on the fabrication of natural fiber composites and machining studies. He was an Editor for the third International Conference on Advanced Manufacturing and Automation (INCAMA) 2018. Now he is working as an Associate professor in the Department of Mechanical Engineering, Kalasalingam Academy of Research and Education since, 2012 .

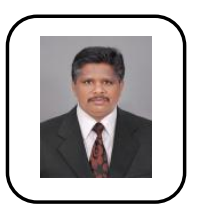

Dr. N. Rajini obtained his Bachelor's degree in Mechanical Engineering from Manonmaniam Sundaranar University, Tirunelveli in 1999. He was awarded his Master's degree in Engineering Design from Anna University, Chennai in 2004. Then he completed his PhD in Composite Materials from Kalasalingam University, Krishnankoil in 2013 and then his post-doctoral fellowship in Ghent University, Belgium in 2015. He was a visiting scientist at INTROP, Malaysia and KMUTNB, Bangkok. He is a life time member of ISTE. He brings to his position in a well-balanced background in polymers. He has published more than 70 international journals and also published more than 30 papers in International Conference proceedings. He was a CoPrincipal Investigator for a funded project of Tamilnadu State Council for Science and Technology. Currently, he is working as a Professor in the Department of Mechanical Engineering, Kalasalingam Academy of Research and Education since, 2004.

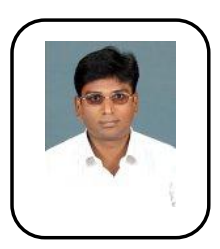

Dr. S. Rajesh obtained his Bachelor's degree in Mechanical Engineering from Alagappa Chettiar College of Engineering and Technology; Karaikudi affiliated to Madurai Kamaraj University (2002) and completed his Master's degree in Computer Aided Design from the Alagappa Chettiar College of Engineering and Technology, Karaikudi affiliated to Anna University Chennai (2008). Then he was awarded his $\mathrm{PhD}$ in Mechanical Engineering from Kalasalingam Academy of Research and Education, Krishnankoil in 2014. He published more than 10 papers in the reputed journals and also published more than 17 international conference papers. Presently, he is working as an Associate Professor \& Head of Department of Mechanical Engineering, Kalasalingam Academy of Research and Education with more than 15 years of teaching expertise. 